Chapter to appear in "The Science of the Mind: The 21st Century" (Robert Solso, Ed.)

FACT: The First Axiom of Consciousness and Thought

\author{
Endel Tulving \\ Rotman Research Institute of Baycrest Centre, \\ University of Toronto, and \\ Center for Neuroscience and Department of Psychology, \\ University of California at Davis
}

Writing about the future is much easier than writing about the past: One need not worry about whether what one writes is true or not, or even about whether what one says is believable or plausible. But there are several ways of making absolutely sure that one's ruminations about the future will not come back to haunt one, directly or indirectly. A rather effective stratagem is to consider the future whose happenings are too far away for anyone alive today to be able to verify. Another one is to refuse at the outset to accept any responsibility for what one says.

Shortly after I accepted my assignment from the Editor of the present volume, I experienced a remarkably fortunate incident: I was visited by a young person of indeterminate gender who said that it was an emissary of a committee that had become aware of my problem of writing something meaningful about the brain $/ \mathrm{mind}$ sciences of the 21st century and that the committee had decided to send it to help me. What was remarkable was not the offer of help as such but rather the fact that the visitor said that It was visiting me from the future, from the year 2096 A.D. to be exact, and that the purpose of the visit was directly connected with my assignment. The thing explained that despite Its relative youth (It did not mention the age, but looked forty-something-ish to me) and the fact that It had not yet completed its formal education, It had developed some interest in the history of sciences. Among other things, It had recently completed a 4.4 megabyte Condensed History of C-Sci in the 21st Century that had qualified It for membership in the committee that It now represented. It offered to share the contents of Its $\mathrm{CH}$ with me. Being of the mischievous kind, however (as It freely admitted upon questioning), It stipulated that I could only read the compendium, that I could not copy it or take any written notes, and that if I wanted to use the 2096 history of the past as a basis for my 1996 predictions about the future, a thought that indeed had already occurred to me, I was welcome to do so, provided that I relied on my TACIT memory ("Text-Analysis-andComprehension-of-Infinite-Transversality" in translation into 1996ese, It kindly explained). I cleverly refused to waste time on further discussion of either that term or the issue of the 2096-style classification of memories). Thus, no notes or copies or tangibly accessible records of any kind--I had to rely purely on mind.

Therefore, the wobbliness and incompleteness of what follows are to be attributed to the infelicities of my TACIT memory; the account itself that I read was exceedingly clear and complete. Especially remarkable was my own reaction to what I read: time after 
time I was struck with the lucidity of the story, with its unmistakable character of 'of course--it could not have been otherwise--but naturally--indeed, self-evidently true--how could we have missed it back in 1996?' Just about everything I read in the compendium about the early 21st century made perfect sense to me, although I began struggling with the developments after about 2020 and essentially had to give up trying to understand the details after 2040. This is also why, despite my essay being all about C-Sci in 2096, it deals mostly with the early 21st century.

What follows, then, is what my TACIT memory informs me of what I read. I cannot be sure of course how veridical everything is. Fortunately, however, because there is no such thing as a 'true history' anyway, some additional noise introduced into the fallible account of history by the fallibility of human memory is not going to change anything very much: we still end up with a fallible account. It is like adding infinity to infinity and still getting only infinity. The only thing that I am reasonably sure about is that the various footnotes [identified as such in the general text by italics] were in the original, apparently placed into the account by various committees or their members at different times, with a few contributed by myself by way of explicating what I had read, or communicating what It had said.

Prehistory of C: The Late 20th Century

In the early days of C-Sci there was science but no C. As late as the 1990s, what we today know as $\mathrm{C}$ was referred to in English by the cumbersome term 'consciousness.' The topic was immensely popular, probably because its earlier suppression: consciousness had been a taboo word in science for the most part of the 20th century. Of all the terms designating something that no one could define, or observe, or point at, or describe, or measure--'consciousness' was by far the most fashionable thing to talk about. A truly rich literature was created on the topic, contributed to by scientists representing all existing disciplines, as well as many others without any discipline.

A curious custom at the time was to designate many things other than consciousness with the same term. Apparently most of the early thinkers thought these other things were somehow meaningfully related to consciousness, and because of scarcity of words in any language, especially English, they had decided to let the same term stand for everything. For instance, while they referred to what we think of as $C$ as 'consciousness' they, or at least some of them, also believed that lifeless machines were 'conscious,' that is that machines could 'have' consciousness. Also, most of the time they did not make any distinctions between concepts that today are distinguished, such as 'consciousness' and 'awareness,' or 'consciousness and attention.' Even more mysteriously, they identified 'consciousness' with grespy. ['General responsivity' in the early 21st century, 'arousal' and 'alertness' during the heyday of folk psychology]. Historians are a bit clearer on the reasons for this latter feat of duplicity--but that is another story. 
The terminological confusion contributed greatly to the state of affairs that some contemporaries thought was sorry and sad while others labelled exciting and promising. There were of course attempts made by rare individuals to try to straighten out the terminology, but these efforts came to nought, for two reasons: (i) Few people were interested in what others were saying, and (ii) It is a well known fact that the terms of a scientific discipline can be no better than its concepts. Because concepts can only emerge from an interplay between observing nature and thinking hard about the observations, and because there was little in the early (late 20th century) study of consciousness that could be regarded as empirical observations of consciousness, the concepts of consciousness had not changed over many hundreds of years.

Indeed, the lack of 'hard' facts about consciousness was probably the major determinant of the state of affairs. There were essentially two kinds of thinkers interested in and committed to a scientific study of consciousness, and the efforts of neither kind helped much with the dearth of facts and verifiable phenomena about consciousness. The first kind did not particularly care about anything other than the 'facts about consciousness' that were obvious to them through the exercise of their own intelligence. These people could be readily identified by examining their papers and books on consciousness: There were no data in them, no tables, no graphs, no measurements, indeed usually no illustrations--just words. [This essay here is a perfect example of the genre.] The second kind, who frequently complained about the first kind, did care about and did include various kinds of data in their published works. Their efforts, however, usually floundered on the general inability of researchers to extricate $C$ from other aspects of mental activity. Even when, towards the end of the 20th century, memory researchers began to distinguish between what they called 'conscious' and 'nonconcscious' memory, it was never quite clear exactly in what sense the distinction was made: Everyone agreed that test-persons exhibiting conscious memory were as conscious as those engaged in nonconscious memory. Some timid attempts were made to attribute the different states of $\mathrm{C}$ to the contents of memory, but they did not work, because it was not known how to measure the consciousness of a remembered bit of information without the mediation of the (always conscious) test-person. [As we will see later, the problem was solved by making it disappear by the magic of what came to be known as The First Axiom.]

Thus it was that a great deal was written about 'consciousness,' but little was achieved. Endless energy was wasted talking about consciousness, especially towards the end of the 20th century, when the term became a true buzzword and exquisitely fashionable. Conferences were organized, books were written, journals were established, prizes were given about, on, and around consciousness, and thinkers interested in and committed to a scientific study of consciousness competed with one another in making claims about designated regions in the brain where their theories said consciousness resided. It was all preparadigmatic, however, to use the terms of Thomas Kuhn, a perceptive 20th century thinker. 
A major symptom of the preparadigmatic nature of the enterprise was the neartotal lack of agreement on anything pertaining to consciousness. At the time when scientific conferences still adhered to the primitive form in which individuals lectured to large audiences, it was nearly impossible to go to a conference on consciousness, with scores of speakers, and find anyone who had anything agreeable to say about anyone else. The topics were always the same, having to do with issues such as what consciousness is and what it is not, whether it exists or does not, whether it is real or epiphenomenal, whether it can be studied or not, whether respectable scientists (like, for example, molecular biologists) should be studying it, or if they were, whether they should admit it publicly, and in general what it means to study consciousness 'scientifically,' given all the doubts about its existence to begin with. Large numbers of papers, ['paper' was the 20th century term for scifiles, because they were actually typed on paper (sic!)], and many sections of papers, were entitled 'The problem of consciousness.' [This was another quaint custom of unknown origin that keeps baffling our historians, because there were few scientific papers written, in any century, under the comparable titles such as 'The problem of universe,' or 'The problem of life,' or 'The problem of behavior,' and it was not at all clear why these other huge categories invented by the human mind had escaped being problematic.]

The Beginning of the End?

As the reader can surmise, the 'Problem of Consciousness' was in deep trouble near the end of the 20th century, and it seemed to be slipping deeper into it year by year. Its future was decidedly bleak. Some made heroic efforts to resuscitate the ghost of consciousness by using PET to identify brain activity of test-persons who did nothing other than think conscious thoughts. Yet these efforts ran aground when the technical experts pointed out that the findings were meaningless, because the correlational nature of the data were ambiguous and essentially uninterpretable. One could surmise that the data showed the effect of the brain on the PET camera, but one could equally readily argue that the data in fact reflected the effect of the PET camera on the test person's brain. This is why the PET studies of consciousness just fizzled out. [By way of a sad footnote it should be mentioned that one old professor, who had dabbled in PETting of the mind, had to be sheltered, because through all his waking hours he kept shouting, over and over again, in a loud voice, : "I knew that correlation was an invention of the Devil, I knew it, I knew!"]

Just when the fortunes of the study of consciousness were at their lowest, and the stories of the 'Problem of Consciousness' read at their bleakest, things started to change again, and in fact to turn around, and eventually blossom into C Science, or C-Sci as we say. The turning point was initially imperceptible, and many historians at first thought that it was so for a good reason: there was in fact no single cause of the turnaround, no single event, or even a series of events, that could have been pointed at and declared to be 
the markers of the 'birth' of C-sci. It was only the remarkable and indefatigable ingenuity of our historical committees that led to the revision of the history. Many happenings have now been identified that could be mentioned as playing a pivotal role in the inevitability of the unfolding of the $C$ universe according to what now seem to have always been its natural laws. Our committees have in fact been able to pinpoint a number of 'Significant Historical Happenings' (SHHs). They have further distinguished between minor SHHs and major SHHs.

An example of a minor $\mathrm{SHH}$ is the dazzling insight of a first-year graduate student at the University of NIET (Northern Independent Eastern Townships, once a part of a country called Canada), at the turn of the millennium, that the cumbersome and nonfunctionally long but exceedingly popular and frequently used word 'consciousness' could be replaced with the word $C$ which would serve the purpose as aptly and distinctively as 'consciousness. [From early on she was fond of telling the story how she had recognized the blinding nature of her insight immediately, because the thought had been instantly followed by a flash of light brighter than a thousand suns. Later in life, as she became old and famous as a sciam--'science administrator,' one of the most popular and revered careers in the second half of the 21st century, a subcategory of 'government bureaucrat'--she came to believe that the light had in fact accompanied the thought, and still later that it had most certainly preceded and thereby inspired the brilliant insight.] Her proposal to replace 'consciousness' with C, surprisingly, was almost immediately accepted, thereby greatly shortening speeches and scifiles about C. It was more convenient, indeed less painful, to refer to C-scientists, or C-ers, as we say today, rather than to use the tiresome phrase 'thinkers interested in and committed to a scientific study of consciousness' or any of its tedious equivalents.

Another minor significant historical happening that has been identified as relatively noncontroversial was the gradual switch [remember the initial imperceptibility?] from "What is the problem of consciousness?" which had been the central issue at the end of the 20th century to "What is the matter with the people that are interested in and committed to a scientific study of consciousness?" The redirection of the focus of concern had no single identifiable origin, and seemed to have simply risen from the enormous frustration felt by many as mist rises from a marsh. At one point it must have become increasingly difficult to further ignore something that is exceedingly clear to us, with our wisdom of hindsight: Given the enormous effort made by large masses of thinkers interested in and committed to a scientific study of consciousness it was most incongruous that nobody really knew much more about consciousness at the end of the 20th century than William James and other enlightened minds had known at the end of the 19th. [Some observers even liked to liken the story of $C$ to the story of parpsy-"parapsychology' of the old. In parpsy, too, masses of highly intelligent practitioners had their minds wonderfully concentrated on obviously interesting problems, they had at their disposal all the tools of modern science, they observed and measured and described and used t-tests and drew conclusions, they used intuition, logic, and the Bayesian 
theorem, yet all to no avail: a hundred years later they were where they had been a hundred years earlier.] At any rate, these and similar kinds of thoughts, totally unacceptable for almost a hundred years after William James, were at the root of the shift of emphasis from $C$ to $C$-ers. The assumption was that if one could fix the C-ers the problem of $\mathrm{C}$ would also be fixed.

The 2018 TeleCongress

It is the firm belief of most history committees, although there is little direct evidence to support it, that the role of the gradual shift of the focus of concern from $C$ to C-ers was much more profound than people realized at the time, because the shift prepared the ground for one of the most profoundly important major SHHs in the history of our subject. This event, which transpired in 2018, was a virtually assembled international telecongress sponsored by NATO, the reborn SEATO, and HFSP to solve what by then had become generally acknowledged as the "Problem of C-ers." The problem was, specifically, "What are we to do with them?" The world governments had already made their decision, which most decisively did answer the question, but they needed the international congress to prove the wisdom of the decision.

The congress participants [they will be referred to as 'delegates' in this essay, although in 2096 they were known as 'telparts'] were typical for the age--a mixture of government bureaucrats representing all six levels of government, their advisors, lawyers, accountants, and a sprinkling of representatives of the public, together with some scientists, including some bona-fide C-ers. The idea that science was far too important to be left to scientists had been gaining ground extrascientifically in the 20th century. Its growth culminated in the establishment of comsci ["Committee science" in the 1996 parlance] with its own unique but now widely known procedures, practices and traditions, including the one of not contaminating scientific conferences with large proportions of scientists. The idea, ironically, mirrored another similar idea that had been brewing intrascientifically, within scientific circles, namely that publication of research findings is far too important to be left to those who had done the research. [There were many reasons for it, but the most telling argument was that researchers are too close to their projects and experiments to be able to render an unbiased assessment as to what it was that they had done, why they had done it, and what the findings meant.] The remedy of the problem, as already mentioned, paralleled the extrascientific developments: scientific publications came to be written by committees, consisting of editors, consulting editors, editorial consultants, referees, reviewers, and other experts. It was the committees that wrote the reports, on the basis of the data provided by researchers. The researchers were initially included as co-authors, but eventually a more satisfying solution was adopted: the committee would thank the researchers in a footnote for their contribution to the joint research. This was the origin of what by the beginning of the 21st century had been known as 'compub' ['committee publishing']. But this, too, is another story, and we should not get distracted from the main line. [Narrator's note: I cannot resist 
the temptation, however, of just mentioning, very briefly, what It, the emissary of the 2096 history committee, told me in private discussions when It visited to let me read the compendium. In the early days of comsci, scientists offered a great deal of resistance to the plans made for them by the government bureaucrats, like the peasants did in the Soviet Union when Stalin forced collectivization on them. They referred to the governments' efforts as 'alien obstruction' before the phrase was decreed politically incorrect and its use punished by having the offenders wear baseball caps, the visor pointing right, to committee meetings. But only when the governments resolutely put an end to the counterinsurgency through the venerable stratagem of stopping paying any and all research expenses of scientists did most scientists get the message and abandoned the fight as futile. Some took early retirement, others retrained as government bureaucrats, took jobs as their advisors, or became lawyers, accountants, and mental health care workers looking after the remaining scientists.]

The agenda of the 2018 congress was long, detailed, and thorough. The problem was that many of the delegates, all brilliant minds, had been C-ers in their previous careers, or had C-ers up in the family tree, or had read and heard enough about $C$ to feel fully qualified to talk about $C$. Thus it came about that instead of immediately coming to the grips with their mission, to seal the fate of C-ers, the delegates decided to spend some time initially on what the participants later described as the 'last-gasp effort to solve the problem of C.' At that point, not surprisingly, it took only two short days of debate for the telediscussion to veer around to the seductively alluring and beguiling problem of machine consciousness. The delegates then spent the next 16 days in furious, frequently acrimonious and always emotionally charged discussion of the topic.

Aristotle to the Rescue

In the late evening of the 18th day of the telecongress, with no end of the debate in sight, a young scholar of Sanskrit, appointed to the congress as a delegate by the Committee for the Protection of Incomprehensible Minor Scholars, made a proposal that changed the history. Her name, Geanne Ovida Darche, was unusual, but since names had been getting more and more unusual over many preceding decades, delegates paid more attention to, and thereby became more aware of, what she had to say than her name. [For brevity's sake, in what follows, only her initials be used.]

G.O.D. was not only at home in Sanskrit, but in 46 other dead languages. She also knew everything about what in the 19th century had been called 'classics.' Her suggestion to the delegates was stunningly original: she proposed to solve the problem of machine consciousness by using Aristotelian reasoning. She explained to the delegates who Aristotle had been, how reasoning had been used in the past to solve problems, how Aristotle even had thought it could be used to arrive at the truth, and how Aristotle's system had worked. [Aristotle's name and his method of arriving at the truth were unknown to most delegates for two reasons. First, general knowledge of dead 
philosophers had been declining precipitously ever since the governments had decided, around the turn of the millennium, that "There are no votes in the humanities," and told the universities to stop teaching humanities. Second, the 'modern' values had been eroding for a while even in the 20th century and they were eventually replaced by 'postmodern' values: facts were replaced by faith, logic by beliefs, and truth by feelings.]

G.O.D. then presented her case forcefully and articulately. [Historians' opinions are divided as to whether she had carefully planned the operation for over some time, or whether it had come to her naturally on the spur of the moment. In either case, all agreed that it was startlingly brilliant.]

In the beginning, G.O.D. presented her first syllogism, as follows:

Premise 1: Matter can exist without life

Premise 2: Living matter can exist without consciousness

Conclusion: Consciousness can exist regardless of whether the conscious system is alive or not.

There was little discussion of the conclusion, either because of the late hour or because there was nothing to discuss. [A very old man tried to question G.O.D. on the legitimacy of her syllogism, muttering something like 'it does not look like a syllogism to me,' but G.O.D. just looked him deeply in the virtual eye, and he fell silent.] After the delegates had voted both premises true, and G.O.D. had explained that therefore the proposed conclusion was syllogistically valid, everybody cheered. At that point G.O.D. pulled out her first trump card. She pointed out that although the conclusion was a valid conclusion, that is, logically conclusive, it was empirically inconclusive. She explained that it was this theoretical problem--logically conclusive but empirically inconclusive conclusion--that had been responsible, throughout the 20th century, for (i) the interminable discussions about machine consciousness that had wasted thousands of C-er years, and (ii) the fact that the discussions were interminable. [Although many delegates could not quite follow G.O.D.'s reasoning, it felt good, and no one demurred.]

Then G.O.D. proposed her second syllogism:

Premise 1: Life cannot exist independently of matter.

Premise 2. Consciousness cannot exist independently of living matter.

Conclusion: Consciousness cannot exist unless the conscious system is alive.

She also offered a corollary to the conclusion.

Corollary: Artifacts that are not alive, even if produced by living systems, cannot be conscious. 
[According to the personal testimony of the 2096 emissary, and not part of the official record, it had been verified that at this point some delegates became alarmed, because they thought she had said 'coronary.' They calmed down, however, when G.O.D. explained the difference. According to the same personal testimony, again not found in the records, the same very old man again tried to question G.O.D. on her syllogism, but when G.O.D. asked other delegates how they felt about the syllogism, and they said they believed the syllogism was a syllogism, the old man was ignored for the rest of the proceedings.]

Delegates unanimously voted Premise 1 to be true. There was some discussion about Premise 2. Some delegates questioned it, because, they said, there was no experimental evidence for it, or even any other kind of empirical evidence. But by this time general ennui really had set in, and the debate became pretty one-sided. G.O.D. claimed that one cannot question Premise 2 on the grounds of empirical evidence any more than one could question Premise 1 on the same grounds, and pointedly asked whether any delegate had contrary opinions. None did. Not wishing to leave anything to chance, however, G.O.D. decided to drive her point home by asking whether any delegate had any empirical proof of the existence of a real world outside their own phenomenal experience, and when none did, she asked how many of them nevertheless thought that the world really existed. All did. With the audience thus softly prepared, G.O.D. invited another young scholar of Sanskrit, whose name was Jeanne Charisma, and whose qualifications were very similar to those of G.O.D., and whom G.O.D. apparently knew quite well, to explain the doctrine of solipsism to the delegates. [Knowledge of philosophical ideas had gone the way of philosophers.] As J.C. delivered her monologue, most delegates kept solemnly nodding their heads, as was clearly seen on the transvideo.

J.C. then took the opportunity of occupying the center and reminded the delegates that if there were any secret doubters left they should realize that accepting Premise 1 but rejecting Premise 2 would imply that there may be more things in the universe that are conscious than there are things that are alive, and that that surely could not be true, because it would violate the Third Law of Evolution. [Again, some historians have speculated that the powerful argument delivered by J.C. was not totally unrehearsed, but evidence on the point has remained fuzzy.] By this time all the delegates had pushed the 'Call Vote' button, and when the vote was taken, the Conclusion of G.O.D.'s Syllogism 2 and its Corollary were overwhelmingly accepted as valid.

FACT: The First Axiom of $\mathrm{C}$ and $\mathrm{T}$

In the dying minutes of the telecongress, with the weary delegates heady with a warm glow of feelings of accomplishment--after all, they had managed to put their collective finger on at least one of the C-er problems--the second young Sanskrit scholar, J.C., proposed that for the conclusion just accepted to be really effective in guiding the future thinking about $\mathrm{C}$, it would be desirable to elevate the Conclusion and its Corollary 
to the status of an Axiom. The proposal was overwhelmingly accepted. There were no contrary votes, although 14 delegates, representing computer, chip, and cable manufacturers, abstained. Quickly capitalizing on the now irrepressibly jubilant mood of the delegates (some spontaneous singing of Beethoven's 'Ode to Joy' was heard in the cosmic background of the universal transmission of the proceedings) G.O.D., seconded by J.C., made what she promised was her final proposal: To extend the First Axiom from $C$ to $\mathrm{T}$ [ $\mathrm{T}$ by the year 2096 had been derived from the word 'thought' by the sociolinguistic mechanism subserving Zipf's law; thought and thinking preoccupied the society almost as much as C, E, and X, where E stands for what was generically known as 'entertainment' back in the 20th century, and X stands for what in the dying days of that century had been called 'gender'.] She explained that even without the cumbersome reasoning required by Aristotelian syllogisms, or even without reasoning by analogy, it was exceedingly clear that thought was always accompanied by awareness, and because awareness was nothing but expression of consciousness, talking about nonconscious thought and related ideas ('thinking machines') made sense and was excusable only in situations where it was necessary to come up with the most powerful example of the concept of 'oxymoron'.

Thus came about what later in C-sci became known as The First Axiom of C and T, or The FACT--'If a thing is not alive, it cannot be conscious, nor can it think.' After the fateful congress of 2018, it has never been seriously questioned. Indeed, at our own time, near the end of the 21st century, it would be difficult to find an educated person over 8 years of age who does not think of The FACT as something whose verity is utterly beyond any doubt.

The acceptance of the First Axiom turned out to be a truly pivotal event in the history of C. Not only did it save the C-ers and their activities from experimental extinction envisaged by the governments (after the 2018 congress C-ers seemed to be coming out of the woodwork in hordes), it also provided a surprisingly clean new beginning to the study of $C$. [It was surprising, because no one would have predicted that as slight a realignment of thought as that involved in decisively rejecting the possibility of machine consciousness would make much of a difference in the study of those aspects of $\mathrm{C}$ that were, or could be seen as being, free from any dependence on the issue. Nevertheless it did. It was as if the C-ers' creative powers were set free from the ominous influence of a dark cloud that had been hanging over them, not physically preventing them from thinking productive thoughts about $C$, but somehow paralyzing them by its mere presence.]

The brilliance of the solution crafted by G.O.D. and J.C., although doubted by some traditionalists at the outset, became more generally clear over some twenty years of thought following the 2018 congress. By 2040 everybody agreed that it had saved C as an object of scientific interest. [This indeed is why some referred to the First Axiom as 'salvation,' rather than merely as a 'solution.] However, different people liked different things about it. 
Some thought the solution was brilliant because it freed thinkers from being frustrated by the historical Turing problem, doing so the same way that Alexander the Great had dealt with the Gordian knot. It was now realized that the Turing problem was not just trivial, but also boring: Surely you can build clever machines, or even intelligent ones, whose actions can fool all the people some of the time and some people all the time. So what? The important issue is not machine intelligence, but machine $\mathrm{C}$. And $\mathrm{C}$ is what the machines do not have, by definition, like an ordinary human does not have wings, or silicon chips in its frontal lobes, by definition. [This was yet another breakthrough discovery: There may be people who will always want to argue about machine consciousness--after all there are people who believe that the earth is flat--and we can let them do that. No problem, as they used to say. But machine $C$ is ruled out the same way as studies of sexual reproduction of machines is ruled out.]

Other commentators were full of admiration for the First Axiom, because it most ingeniously shifted the whole burden of decision from the difficult 'How do we know that $X$ is not conscious?' to the much easier 'How do we know that $X$ is alive?' Most people were ready to believe that the criterion of life was DNA, and thus they agreed on how to distinguish living things from nonliving ones: "Does it or does it not have DNA that looks like DNA and acts like DNA and comes about the same way as does DNA?" So they were happy that they did not need the Turing test, or any exotic room test, or any kind of a symbol-crunching test. All they needed, they said, was a test for DNA. Once they had established that the object under scrutiny had DNA they could proceed, and frequently did, to ask and find out what kind of $C$ it did have. If it had no DNA, it had no C of any kind. It was as simple as that.

Still others thought that the main virtue of the First Axiom lay in the clear establishment of $\mathrm{C}$ as a biological phenomenon, freeing it from the strictures of quantum mechanics as much as from the dogmas of metaphysics. [Although some argued that quantum mechanics was quite relevant to the understanding of $C$, the consensus was that although true in principle, the claim was in the same logical category as the claim that principles of internal combustion are relevant to the understanding of the dynamics of traffic jams.]

Finally, a small minority liked the thought of all the trees (in the earlier years of the debate) and all the electricity (later on) that had been saved [salvation again?] by eliminating the endless, futile, and totally unneeded arguments over the possibility of consciousness of rocks, marble statues, waterfalls, windmills, cuckoo clocks, household robots, desk-top computers, and Barbie dolls who speak accent-free Estonian.

The important point is that there was universal agreement that the First Axiom had in fact totally changed the history of C. The FACT was taught in all schools and thus it 
became not just generally known but greatly admired. Many mortals came to think of it as the most lucid human thought ever expressed. Many theologians were surprised when told the story of its birth, because on the pure face of it, it was difficult to reject the impression that it must have been of divine origin. 


\section{AUTHOR'S NOTE:}

The ideas expressed in the essay, like all other ideas that scientists have, owe their existence to an unknown mix of what has already been stated by others and what has not yet been expressed, or not yet been expressed in quite the same form. It would be impossible to do perfect justice to all the previous thinkers who have wrestled with the many problems that the term 'consciousness' can conjure up in the active minds of conscious people. I know explicitly that my own thoughts on the matter have been stimulated by at least the papers and books that are listed in the bibliography, and probably many more. It is safe to assume, therefore, that any similarity between my thoughts and those expressed before by many others is highly unlikely to be purely accidental. The same is probably true of the similarity between thoughts in this essay and the similar ones that can be found in papers and books I have not listed. As of Jan 1, 1996, there were over 10,000 entries that responded to the key-word search for 'conscious' or 'consciousness' (restricted to human studies in the MEDLINE (1975-1995), and over 18,000 entries that responded to the same search in the PsycLIT (1970-1995). The richness of the literature is largely attributable to the fact that just about anything that has something to do with the behavior of organisms and cognitive phenomena of human beings has been seen to be related to consciousness. Thus there are endless papers (mostly book chapters, because these do not go through very strict refereeing process) written on consciousness and $\mathrm{X}$, where $\mathrm{X}$ might be any one of hundreds of items such as action, activity, amnesia, anaesthesia, aphasia, artificial intelligence, attention, biology, brain, classical conditioning, cognition, cognitive science, computational models, connectionist models, cortical activity, dreaming, emergence of language, evolution, experience, frontal lobes, hemispheric laterality, hippocampus, intelligence, intentionality, language, lateral asymmetry, learning, memory, mental imagery, mind, neglect, neurotransmitters, ontogenesis, parallel distributed processing, perception, phenomenology, phylogenesis, prosopagnosia, qualia, quantum physics, reductionism, scientific method, sensation, skill learning, sleep-waking cycle, spatial organization, teleology, temporal organization, theory of relativity, thought, time, and universe.

E.T.'s research is financed by an endowment by Anne and Max Tanenbaum in support of research in cognitive neuroscience, and by a grant from the Natural Sciences and Engineering Research Council of Canada. 


\section{BIBLIOGRAPHY}

Baars, B.J. (1988). A cognitive theory of consciousness. Cambridge, England: Cambridge University Press.

Bunge, M., \& Ardila, R. (1987). Philosophy of psychology. New York, NY: Springer.

Cabanac, M. (1996). On the origin of consciousness, a postulate and its corollary. Neuroscience and Biobehavioral Reviews, 20, 33-40.

Crick, F., \& Koch, C. (1992). The problem of consciousness. Scientific American, 267, 152159.

Delacour, J. (1995). An introduction to the biology of consciousness. Neuropsychologia, 33, 1061-1074.

Dennett, D., \& Kinsbourne, M. (1992). Time and the observer: the where and when of the consciousness and the brain. Behavioral and Brain Sciences, 15, 183-206.

Donald, M. (1995). The neurobiology of human consciousness: An evolutionary approach. Neuropsychologia, 33, 1087-1102.

Farthing, G.W. (1992). The psychology of consciousness. Englewood- Cliffs, NJ: Prentice Hall.

Gardiner, J.M. (1995). On consciousness in relation to memory and learning. In M. Velmans (Ed.), The science of consciousness: Psychological neuropsychological, and clinical reviews. London: Routledge.

Gazzaniga, M. S. (1985). The social brain: Discovering the networks of the brain. New York: Basic Books.

Hirst, W. (1995). Cognitive aspects of consciousness. In M.S. Gazzaniga (Ed.). The Cognitive Neurosciences (pp. 1307-1319). Cambridge MA: MIT Press.

Ingvar, D.H. (1985). "Memory of the future": An essay on the temporal organization of conscious awareness. Human Neurobiology, 4, 127-136.

James. W. (1890). Principles of psychology. New York: Holt.

Kinsbourne, M. Models of consciousness: Serial or parallel in the brain? In M.S. Gazzaniga (Ed.). The Cognitive Neurosciences (pp. 1321-1329) Cambridge MA: MIT Press.

Mandler, G. (1975). Mind and emotion. New York: Wiley.

Markowitsch, H.J. (1995). Cerebral bases of consciousness: A historical review. Neuropsychologia, 33, 1181-1192.

Moscovitch, M. (1995). Models of consciousness and memory. In M.S. Gazzaniga (Ed.). The Cognitive Neurosciences (pp. 1341-1356). Cambridge MA: MIT Press

Perner, J. \& Ruffman, T. (1995). Episodic memory and autonoetic consciousness: Developmental evidence and a theory of childhood amnesia. Journal of Experimental Child Psychology, 59, 516-548.

Revonsuo, A., Kamppinen, M., \& Sajama, S (1994). General introduction: The riddle of consciousness. In A.Revonsuo and M. Kamppinen (Eds), Consciousness in philosophy and cognitive neuroscience (pp. 1-23). Hillsdale, NJ: Erlbaum.

Rugg, M.D. (1995). Memory and consciousness: A selective review of issues and data. 
Neuropsychologia, 33, 1131-1141.

Schacter, D.L. (1989). On the relation between memory and consciousness: Dissociable interactions and conscious experience. In .L. Roediger, III, \& F.I.M. Craik (Eds.), Varieties of memory and consciousness: Essays in honour of Endel Tulving (pp. 355- 389). Hillsdale, NJ: Erlbaum.

Searle, J.R. (1992). The rediscovery of the mind. Cambridge, MA: MIT Press.

Shallice, T. (1988). From neuropsychology to mental structure. Cambridge: Cambridge University Press.

Stuss, D.T., \& Benson, D.F. (1986). The frontal lobes. New York: Raven Press.

Velmans, M. (1991). Is human information processing conscious? Behavioral and Brain Sciences, $14,651-726$.

Weiskrantz, L. (1994). Neuropsychology and the nature of consciousness. In H. Gutfreund \& C. Toulouse (eds.), Biology and computation: A physicist's choice (pp. 323-336). Singapore: World Scientific Publishing. 